\title{
MEK activity controls IL-8 expression in tamoxifen-resistant MCF-7 breast cancer cells
}

\author{
SANGMIN KIM ${ }^{1}$, MYEONGJIN JEON ${ }^{1,2}$, JEONG EON LEE ${ }^{1,2}$ and SEOK JIN NAM ${ }^{1}$ \\ ${ }^{1}$ Department of Surgery, Samsung Medical Center, Sungkyunkwan University School of Medicine, \\ Gangnam-gu, Seoul 135-710; ${ }^{2}$ Department of Health Sciences and Technology, Samsung Advanced \\ Institute for Health Sciences and Technology, Gangnam-gu, Seoul 135-710, Republic of Korea
}

Received October 21, 2015; Accepted December 3, 2015

DOI: $10.3892 /$ or.2016.4557

\begin{abstract}
Although tamoxifen reduces disease progression, tamoxifen resistance occurs during the course of estrogen receptor-positive $\left[\mathrm{ER}^{+}\right]$breast cancer treatment. In the present study, we investigated the possibility that interleukin-8 (IL-8) is a prognostic marker for tamoxifen resistance and aimed to clarify the regulation of IL-8 expression in tamoxifen-resistant cells. Clinically, IL-8 expression is positively correlated with survival in luminal A type breast cancer patients, but not in luminal B type breast cancer patients. In addition, the levels of IL-8 mRNA and protein expression were significantly increased in tamoxifen-resistant (TamR) cells compared to tamoxifen-sensitive (TamS) cells. To determine the regulatory mechanism of IL-8 expression in TamR cells, we analyzed the activities of signaling molecules. Our results showed that the phosphorylation levels of MEK and Akt were markedly increased in TamR cells, but there was no change in the phosphorylation level of p38 MAPK. On the contrary, we observed that elevated IL-8 mRNA expression was suppressed by a specific MEK1/2 inhibitor, UO126, but not by the specific PI-3K inhibitor LY294002, in TamR cells, whereas, we found that overexpression of constitutively active-MEK (CA-MEK) significantly increased the levels of IL-8 mRNA expression in TamS cells. Finally, we investigated the effect of the specific CXCR1/2 inhibitor SB225002 on anchorageindependent growth of TamR cells, and found that the growth was completely suppressed by SB225002. Taken together, our results demonstrate that IL-8 expression is regulated through a MEK/ERK-dependent pathway in TamR cells, suggesting that IL-8 and its receptors may be promising therapeutic targets for overcoming tamoxifen resistance.
\end{abstract}

Correspondence to: Dr Seok Jin Nam or Dr Sangmin Kim, Department of Surgery, Samsung Medical Center, Sungkyunkwan University School of Medicine, 50 Irwon-dong, Gangnam-Gu, Seoul 135-710, Republic of Korea

E-mail: sjnam@skku.edu

E-mail: sangmin3005.kim@samsung.com

Key words: IL-8, poor prognosis, anchorage-independent growth, MEK, tamoxifen-resistant breast cancer

\section{Introduction}

Despite the development of early diagnostics, therapeutic regimens, and targeted drugs, breast cancer is the most common female cancer and the second leading cause of cancer death in women worldwide (1). Approximately 70-75\% of breast cancer tumors express the estrogen receptor (ER), progesterone receptor (PR), and/or estrogen-responsive and ER-dependent gene products (2). Generally, tamoxifen, an ER antagonist in the breast, is used as the chemotherapeutic agent for ER-positive breast cancer patients and bound ER complex competitively prevents the interaction of estrogen with ER $(2,3)$. However, a substantial proportion of the patients who receive tamoxifen treatment are limited by intrinsic and acquired resistance $(4,5)$. Therefore, many researchers have been investigating a variety of strategies to overcome or bypass tamoxifen resistance. Recently, we also reported that unlike gefitinib, neratinib prevents the more effective EGFR and HER2 signaling pathways as well as triggers apoptotic cell death of tamoxifen-resistant cells (6).

Interleukin-8 (IL-8, CXCL8) is a multifunctional proinflammatory chemokine that is upregulated by hypoxia, cytokines and other environmental stresses through activation of transcription factors such as NF- $\mathrm{\kappa B}$ and AP-1 (7,8). Serum IL-8 binds to its receptors CXCR1 and CXCR2, resulting in metastatic invasiveness, early recurrence and worse outcomes (9-11). All of the malignant breast cancer specimens express CXCR1 and CXCR2, whereas only $50 \%$ of the benign breast tissue samples express these receptors (12). In addition, IL-8 is highly expressed in estrogen receptor-negative [ER'] and HER $2^{+}$breast cancers $(13,14)$. The ER significantly decreases IL-8 promoter activity through an estrogenindependent pathway (15). The complex of IL-8 and CXCR2 stimulates VEGF expression in endothelial cells and enhances production of MMP-2 and MMP-9 $(16,17)$.

The aim of the present study was to determine whether IL-8 is a prognostic marker for tamoxifen resistance and to understand the mechanisms underlying the role of IL-8 expression in tamoxifen-resistant cells. We found that the level of IL-8 expression was directly associated with the survival of luminal A type breast cancer patients and was significantly increased in TamR cells. Moreover, IL-8 expression was upregulated through the MEK/ERK-dependent pathway in 
TamR cells. Finally, we observed that anchorage-independent growth of TamR cells was completely suppressed by the specific CXCR1/2 inhibitor SB225002. Therefore, we suggest that IL-8 and its receptors may be a promising therapeutic target for overcoming tamoxifen resistance.

\section{Materials and methods}

Reagents. Dulbecco's modified Eagle's medium (DMEM) was purchased from Thermo Scientific (Hemel Hempstead, UK). Fetal bovine serum (FBS) was purchased from HyClone Laboratories (Logan, UT, USA). Phenol red-free DMEM and penicillin $(100 \mathrm{U} / \mathrm{ml})$ and $100 \mathrm{mg} / \mathrm{ml}$ streptomycin were purchased from Life Technologies (Rockville, MD, USA). UO126 was purchased from Selleck Chemicals (Houston, TX, USA). SB253580 and LY294002 were purchased from Tocris Bioscience (Ellisville, MO, USA). 4-Hydroxytamoxifen (4-OHT) was purchased from Sigma (St. Louis, MO, USA). The secondary horseradish peroxidase (HRP)-conjugated and mouse monoclonal anti- $\beta$-actin antibodies were purchased from Santa Cruz Biotechnology, Inc. (Santa Cruz, CA, USA). Rabbit polyclonal anti-MEK and anti-Akt antibodies (total and phospho-form) were purchased from Cell Signaling Technology (Beverly, MA, USA). Recombinant human IL-8 was purchased from R\&D Systems (Minneapolis, MN, USA). The ECL prime reagents were purchased from Amersham (Buckinghamshire, UK).

Microarray data analysis. We downloaded expression data from a public database [Kaplan-Meier plotter database (http:// kmplot.com/breast)] and analyzed the clinical value of IL-8 expression in luminal A and B type breast cancer patients.

Establishment of tamoxifen-resistant MCF-7 breast cancer cells. TamR was established using a previously reported methodology $(6,18)$. Briefly, to establish TamR, MCF-7 cells were washed with PBS, and the culture medium was changed to phenol red-free DMEM containing 10\% charcoal-stripped steroid-depleted FBS and $0.1 \mathrm{mM}$ 4-hydroxytamoxifen (4-OHT). The cells were continuously exposed to this treatment regimen for two weeks, and the 4-OHT concentration was increased gradually to up to $3 \mathrm{mM}$ over a 9 -month period. Initially, cell growth rates were depressed. However, after exposure to the medium for 9 months, the rate of cell growth increased gradually, indicating the establishment of tamoxifenresistant cells.

Soft agar colony formation assay. TamS and TamR cells were seeded at a density of $5 \times 10^{4}$ cells/well in 6 -well plates in growth medium containing $0.7 \%$ agar $(1.5 \mathrm{ml} /$ well $)$ on top of a layer of growth medium containing $1.4 \%$ agar $(2 \mathrm{ml} /$ well). Growth medium $(500 \mu \mathrm{l})$ with $10 \%$ FBS was added on top of the agar. The cell suspension was plated and cultured in a $37^{\circ} \mathrm{C}$ incubator for two weeks. After two weeks, viable colonies were stained with $0.01 \%$ crystal violet and were then observed using a CK40 inverted microscope (Olympus, Tokyo, Japan) (6).

Flow cytometric analysis (FACS). Apoptosis assays were performed with the Annexin V-fluorescein isothiocyanate (FITC) apoptosis kit-I (BD Biosciences, San Diego, CA, USA), according to the manufacturer's protocol. Briefly, cells $\left(1 \times 10^{6}\right.$ cells $/ \mathrm{ml}$ ) were collected and washed twice with PBS and then resuspended in $500 \mu \mathrm{l}$ of staining solution containing $5 \mu \mathrm{l}$ FITC-conjugated Annexin V and $5 \mu \mathrm{l}$ propidium iodide (PI). After incubation for $15 \mathrm{~min}$ at room temperature (RT) in the dark, cells were immediately analyzed on a flow cytometer. Apoptotic cells were double stained with Annexin V and PI and were then analyzed using the FACS Vantage system (Becton-Dickinson, San Diego, CA, USA). The percentage of cells undergoing apoptosis was determined (6).

Real-time PCR. The total RNA was extracted from the cells using the TRIzol reagent (Invitrogen, Carlsbad, CA, USA), according to the manufacturer's instructions. Isolated RNA samples were then used for RT-PCR. Samples $(1 \mu \mathrm{g}$ of total RNA) were reverse-transcribed into cDNA in $20 \mu \mathrm{l}$ reaction volumes using a first-strand cDNA synthesis kit for RT-PCR, according to the manufacturer's instructions (MBI Fermentas, Hanover, MD, USA).

The gene expression was quantified by real-time PCR using a SensiMix SYBR kit (Bioline Reagents Ltd., London, UK) and $100 \mathrm{ng}$ of cDNA per reaction. The sequences of the primer sets used for this analysis were: human IL-8 (forward, 5'-AGGGTTGCCAGATGCAATAC-3'; reverse, 5'-AAACCA AGGCACAGTGGAAC-3') and GAPDH as an internal control (forward, 5'-ATTGTTGCCATCAATGACCC-3' and reverse, 5'-AGTAGAGGCAGGGATGATGT-3'). An annealing temperature of $60^{\circ} \mathrm{C}$ was used for all of the primers. The PCR was performed in a standard 384-well plate format with an ABI 7900HT real-time PCR detection system. For data analysis, the raw threshold cycle $\left(\mathrm{C}_{T}\right)$ value was first normalized to the housekeeping gene for each sample to get the $\Delta \mathrm{C}_{T}$. The normalized $\Delta \mathrm{C}_{T}$ was then calibrated to the control cell samples to get the $\Delta \Delta \mathrm{C}_{T}$.

IL-8 ELISA. Protein levels of IL-8 were measured using an ELISA kit for human IL-8 (KomaBiotech, Seoul, Korea), according to the manufacturer's instructions, and then a microtiter plate reader was used to read the plate at a $450 \mathrm{~nm}$ wavelength.

Western blotting. The cell culture media (supernatants) and cell lysates were used in the immunoblot analysis for MEK and $\beta$-actin. The proteins were boiled for $5 \mathrm{~min}$ in Laemmli sample buffer and then electrophoresed in 8 or $10 \%$ SDS-PAGE gels, respectively. The separated proteins were transferred to PVDF membranes and the membranes were then blocked with $10 \%$ skim milk in TBS with $0.01 \%$ Tween-20 for 15 min. The blots were incubated with anti-MEK, anti-Akt (total and phospho-form), anti-p38 (phospho-form), and $\beta$-actin antibodies $(1 / 1,000$ dilution) in $1 \%$ TBS/T buffer $(0.01 \%$ Tween-20 in TBS) at $4^{\circ} \mathrm{C}$ overnight. The blots were washed three times in TBS with $0.01 \%$ Tween-20 and they were subsequently incubated with anti-rabbit peroxidase-conjugated antibody $(1 / 2,000$ dilution) in TBS/T buffer. After $1 \mathrm{~h}$ of incubation at room temperature (RT), the blots were washed three times and ECL prime reagents were used for development.

Adenovirus induction. The empty (Lac Z) and adenoviral human CA-MEK cDNA were gifts from Dr Hyunil Ha (Korea 

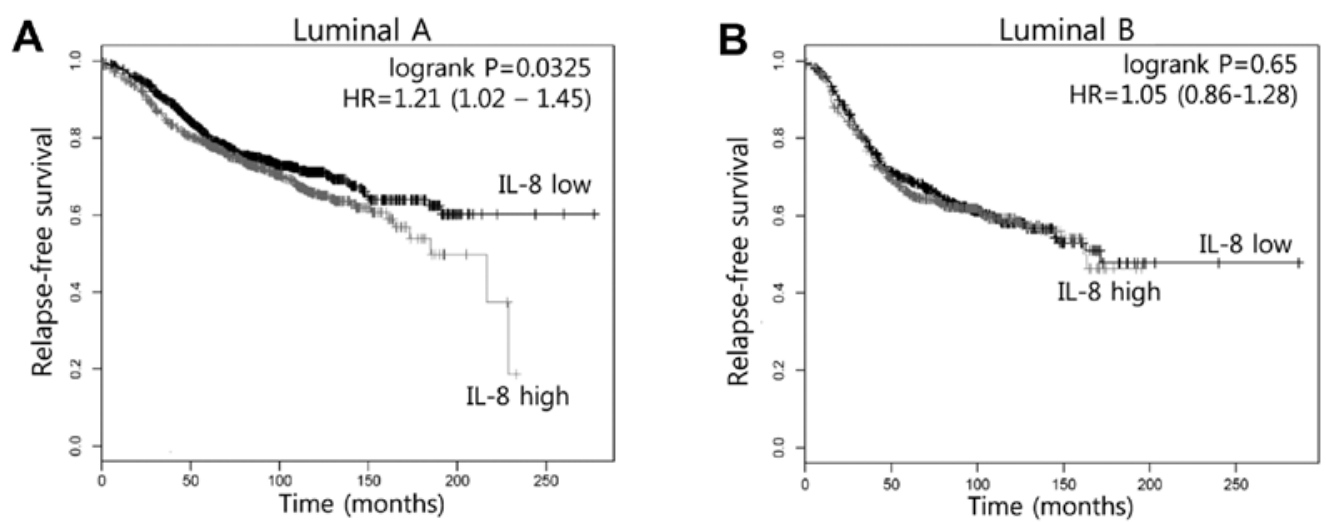

Figure 1. Elevated IL-8 expression is associated with poor prognosis in luminal A type breast cancer patients. We analyzed the clinical value of IL-8 in luminal A and B type breast cancer patients using a public database [Kaplan-Meier plotter database (http://kmplot.com/breast)]. (A) Relapse-free survival of luminal A type breast cancer patients. (B) Relapse-free survival of luminal B type breast cancer patients.
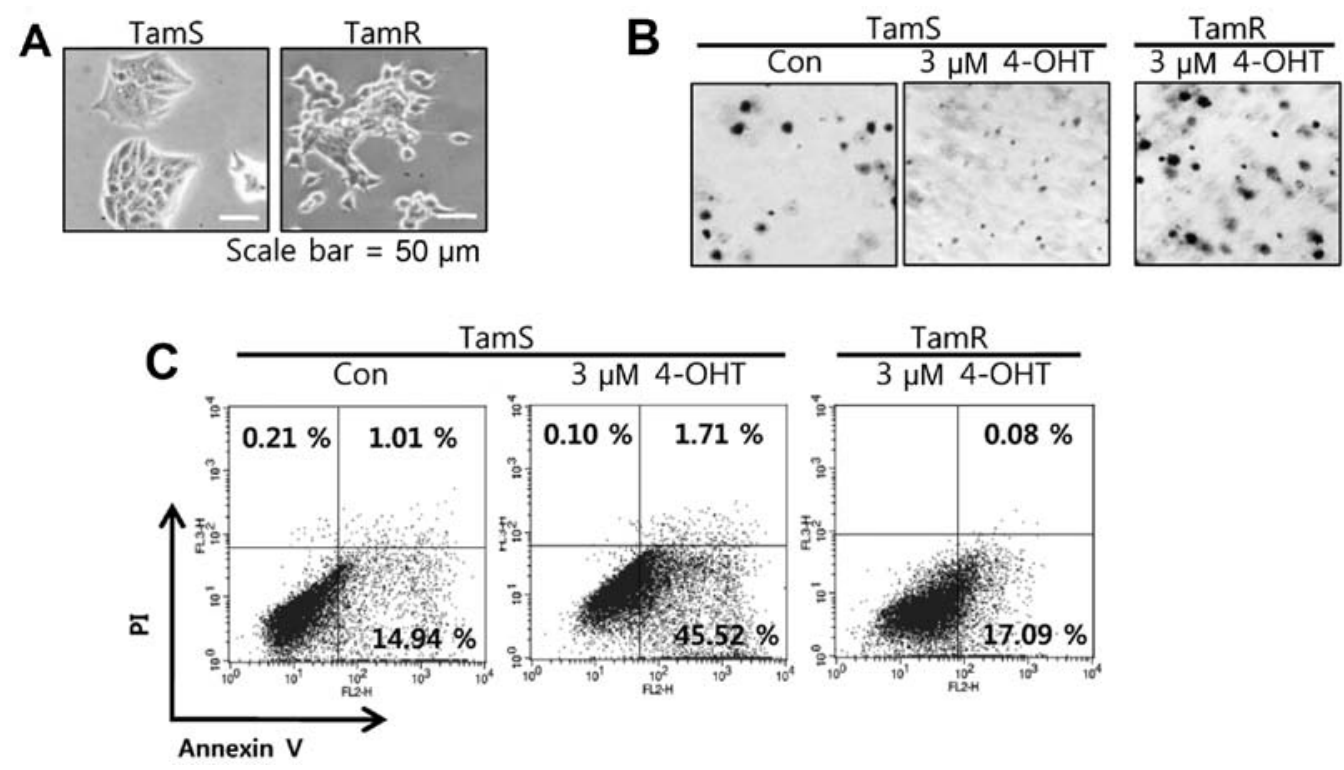

Figure 2. Differential characteristics of TamS and TamR MCF-7 breast cancer cells. (A) Cell morphology of established TamS and TamR MCF-7 cells. (B) Established TamS and TamR MCF-7 cells were seeded in a 6-well soft agar plate with or without $3 \mu \mathrm{M} 4-\mathrm{OHT}$ for two weeks. (C) Established TamS and TamR MCF-7 cells were seeded with or without $3 \mu \mathrm{M} 4-\mathrm{OHT}$ for $24 \mathrm{~h}$. Apoptotic cells were analyzed by flow cytometry. Results are representative of three independent experiments. Con, control.

Institute of Oriental Medicine, Daejeon, Korea). Recombinant adenovirus-expressing human CA-MEK was reproduced into 293A cells and the level of MEK phosphorylation was confirmed by western blotting. Adeniviral vectors were transfected into BT474 cells for $24 \mathrm{~h}$ and then further incubated with fresh serum-free media for $48 \mathrm{~h}$ to detect the level of IL-8 and phospho-MEK and ERK expression.

Statistical analysis. Statistical significance was determined using the Student's t-test. Data are presented as the mean \pm SEM. All quoted P-values are two-tailed and differences were considered significant for P-values $<0.05$. Microsoft Excel was used for the statistical analyses.

\section{Results}

Elevated IL-8 expression results in poor prognosis in luminal A type breast cancer patients. Clinically, we analyzed whether elevated IL-8 levels confer a poor prognosis for human breast cancer patients using a Kaplan-Meier plotter database (http:// kmplot.com/breast). In luminal A type breast cancer patients, patients with high expression of IL-8 showed poorer relapsefree survival in comparison to patients with low expression of IL-8 ( $\mathrm{P}=0.0325$, Fig. 1A). However, relapse-free survival by IL- 8 expression was not significantly different between luminal $\mathrm{B}$ type breast cancer patients $(\mathrm{P}=0.65$, Fig. 1B). Based on these results, we demonstrated that IL- 8 expression may be associated with tamoxifen resistance.

In the present study, we investigated the functional role and regulatory mechanism of IL-8 expression in tamoxifenresistant breast cancer. We established a tamoxifen-resistant breast cancer in vitro model and analyzed differential characteristics of tamoxifen-sensitive (TamS) and -resistant (TamR) breast cancer cell lines. In a recent study, we reported the morphological findings that TamS cells stacked up to form colonies and TamR cells were scattered, loosely packed colo- 
A

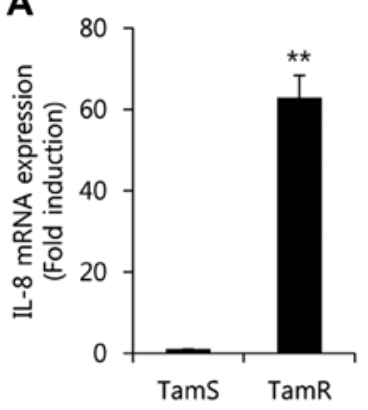

B

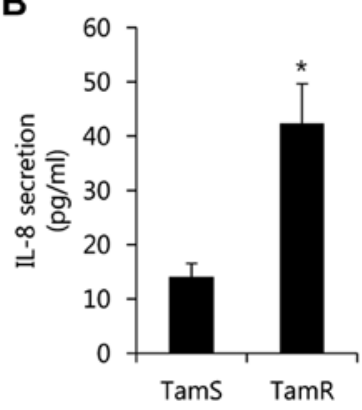

Figure 3. The level of IL-8 expression is significantly increased in TamR cells. After serum starvation for $24 \mathrm{~h}$, each well was further incubated in fresh media with $10 \%$ serum for $48 \mathrm{~h}$. (A) The levels of IL-8 mRNA expression were analyzed by real-time PCR in whole cell lysates. (B) The levels of IL-8 protein expression were analyzed by ELISA in whole cell lysates. Cell morphology was analyzed using a CK40 inverted microscope. These results are representative of three independent experiments. Values are presented as the mean \pm standard errors. ${ }^{*} \mathrm{P}<0.05,{ }^{* *} \mathrm{P}<0.01$ vs. TamS.

nies, with many branches (6). The tumorigenicity of TamS and TamR cells by tamoxifen treatment was analyzed using soft agar colony formation assays. As shown in Fig. 2B, the anchorage-independent growth of TamS cells was completely inhibited by $3 \mu \mathrm{M}$ tamoxifen treatment while growth of TamR cells was maintained. In addition, we also analyzed the apoptotic cell death of TamS and TamR cells after tamoxifen treatment. TamS and TamR cells were treated with or without $3 \mu \mathrm{M}$ tamoxifen for $24 \mathrm{~h}$. The apoptotic cell population of TamS cells after tamoxifen treatment significantly increased by $47.23 \%$ over the control level. However, the apoptotic cell population of TamR cells was not significantly different from that of TamS cells (Fig. 2C).

The level of IL-8 expression is significantly increased in TamR cells. In a previous study, Shi et al (19) reported that elevated IL-6 and IL-8 expression contributes to multidrug resistance in human breast cancer cells. Therefore, we also compared the level of IL- 8 expression between TamS and TamR cells. Our results showed that the levels of IL- 8 mRNA and protein expression were significantly increased in TamR cells when compared with TamS cells (Fig. 3). The level of IL-8 mRNA expression in TamR cells was $62.8 \pm 5.4$-fold higher than that of TamS cells (Fig. 3A). In addition, IL-8 protein expression was also increased by $42.3 \pm 7.3 \mathrm{ng} / \mathrm{ml}$ of the control level $(14.0 \pm 2.5 \mathrm{ng} / \mathrm{ml})$ in TamR cells (Fig. 3B). Therefore, we demonstrated that induction of IL- 8 may be associated with tamoxifen resistance in luminal type breast cancer.

IL-8 expression is upregulated by a MEK-dependent pathway in TamR cells. To verify the regulatory mechanism of IL-8 expression, we analyzed the phosphorylation degree in a variety of signaling molecules in TamS and TamR cells. As shown in Fig. 4A, the activities of MEK and Akt were significantly increased in TamR cells. However, the activity of p38 was not critically different between TamR and TamS cells. Furthermore, cells were treated using specific inhibitors such as the MEK 1 inhibitor UO126, and the PI3-K inhibitor LY294002, for $48 \mathrm{~h}$. After $48 \mathrm{~h}$, the cell lysates were harvested to detect the levels of IL- 8 mRNA expression. The levels

A
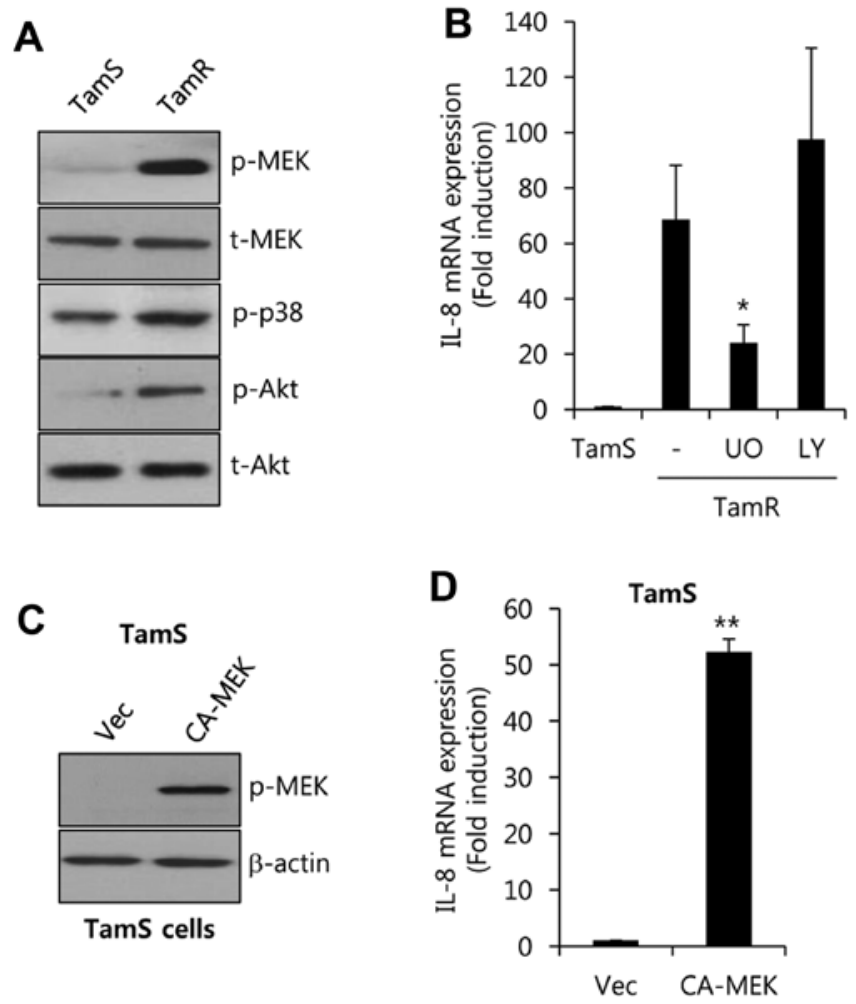

Figure 4. IL-8 expression is upregulated by a MEK-dependent pathway in TamR cells. (A) The levels of p-MEK, t-MEK, p-p38, p-Akt, t-Akt and $\beta$-actin expression were analyzed using the whole cell lysates of TamS and TamR by western blotting. (B) TamR cells were pretreated with $5 \mu \mathrm{M}$ UO and LY for $24 \mathrm{~h}$. The levels of IL-8 mRNA expression were analyzed by realtime PCR. (C) TamS cells were transfected with adenoviral CA-MEK for $48 \mathrm{~h}$. The levels of $\mathrm{p}-\mathrm{MEK}$ and $\beta$-actin expression were analyzed using the whole cell lysates by western blotting. (D) TamS cells were transfected with adenoviral CA-MEK for $48 \mathrm{~h}$. The levels of IL- 8 mRNA expression were analyzed by real-time PCR. These results are representative of three independent experiments. Values are presented as the mean \pm standard errors. ${ }^{*} \mathrm{P}<0.05$ vs. TamR (-), ${ }^{* *} \mathrm{P}<0.01$ vs. Vec. Vec, vector.

of IL-8 mRNA expression were significantly increased by $68.6 \pm 19.7$-fold over that of TamS cells (Fig. 4B). On the contrary, induction of IL-8 was decreased by UO (UO126, a specific MEK inhibitor), but not by LY294002, in TamR cells (Fig. 4B).

Next, we examined whether MEK directly regulates IL-8 expression in TamS cells. We overexpressed adenovirus-delivered constitutively active-MEK (CA-MEK) into TamS cells. As shown in Fig. 4C, we observed that the phosphorylation of MEK was enhanced in CA-MEK-overexpressing cells. Under the same condition, the level of IL-8 mRNA expression was significantly increased by $52.3 \pm 2.3$-fold over the vector-alone levels with CA-MEK overexpression. Therefore, we demonstrated that the level of IL-8 expression is upregulated through a MEK/ERK-dependent pathway in tamoxifen-resistant breast cancer cells.

Inhibition of CXCR1/2 completely abolishes anchorage-independent growth of TamR cells. To inhibit IL-8-induced tumor cell growth, we treated TamR cells with the specific MEK1/2 inhibitor UO126 and the specific CXCR1/2 inhibitor SB225002. As shown in Fig. 5A, anchorage-independent growth of TamR cells was significantly decreased by SB225002 treatment, but 
A

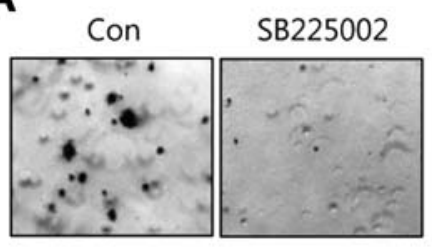

C

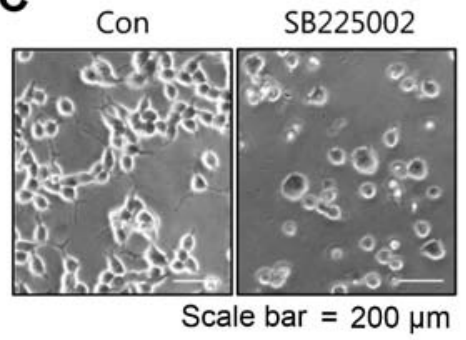

B
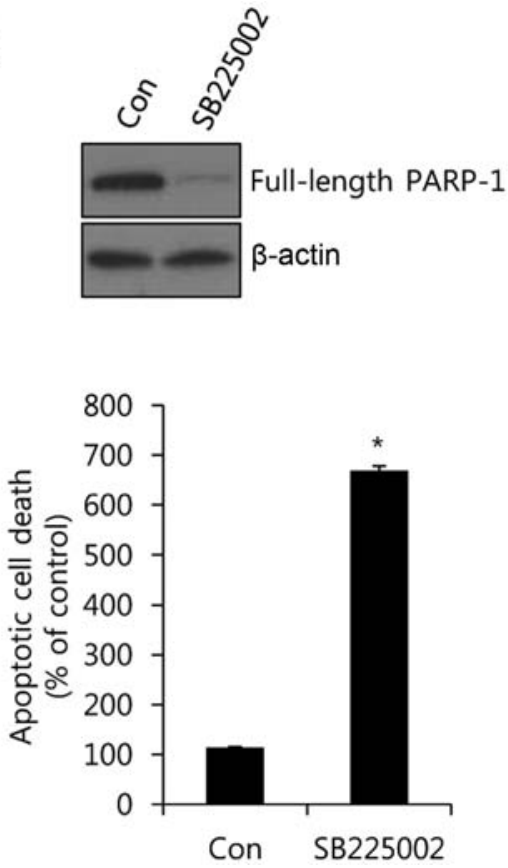

Figure 5. Inhibition of CXCR1/2 completely abolishes anchorage-independent growth of TamR cells. (A) TamR cells were seeded in a 6-well soft agar plate with or without $10 \mu \mathrm{M} \mathrm{SB} 225002$ for three weeks. (B) TamR cells were seeded in a 6-well plate with or without $10 \mu \mathrm{M} \mathrm{SB} 225002$ for $48 \mathrm{~h}$. The levels of PARP-1 protein expression were analyzed by western blotting of whole cell lysates. (C) TamR cells were seeded in a 6-well plate with or without $10 \mu \mathrm{M}$ SB225002 for 48 h. Cell morphology was analyzed using a CK40 inverted microscope. Apoptotic cell death was analyzed by FACS. These results are representative of three independent experiments. Values are presented as the mean \pm standard errors. ${ }^{*} \mathrm{P}<0.01$ vs. Con. Con, control.

not by UO126 treatment. In this study, we suggest that UO126 plays an important role in regulating IL-8 transcriptional activity, while it did not heavily affect anchorage-independent growth of TamR cells.

Next, we investigated the co-relation between SB225002 and apoptotic cell death. We treated TamR cells with SB225002 at the indicated concentration for $24 \mathrm{~h}$ and then harvested whole cell lysates to detect the levels of PARP-1 expression. As expected, the level of full-length PARP-1 protein expression was dose-dependently decreased by SB225002 (Fig. 5B). Furthermore, there were serious changes in cell morphology and the number of apoptotic cells was significantly increased by SB225002 (Fig. 5C). The number of apoptotic cells was $669.5 \%$ greater than that of the control levels after the SB225002 treatment (Fig. 5C). Therefore, we have demonstrated that the complex of IL- 8 and its receptors play a pivotal role in the survival of TamR cells.

\section{Discussion}

Although tamoxifen is a powerful drug for the treatment of premenopausal breast cancer, a substantial proportion of ER-positive breast cancer patients are resistant to tamoxifen therapy (4). Until now, many researchers have sought to understand the mechanism underlying anti-estrogen resistance. Recently, we reported that the level of EGFR expression is significantly increased in tamoxifen-resistant MCF-7 cells and the pan-EGFR inhibitor, neratinib, suppresses growth of tamoxifen-resistant MCF-7 cells (6). Furthermore, IL-6 and IL-8 can activate the ER pathway through an estrogenindependent mechanism in ovarian cancer cells (20). In the present study, we found that IL- 8 expression is increased in
TamR cells when compared with TamS cells. Therefore, we suggest that elevated IL-8 levels may be associated with tamoxifen resistance.

Inflammatory cytokines, including IL-8 and IL-6, regulate breast cancer stem cell self-renewal $(21,22)$. Induction of IL-8 expression by chemotherapy contributes to the enhancement of cancer stem-cell populations and survival, while these phenomena are suppressed by IL-8 directed drugs (22). Moreover, TNBC patients with high B cell and low IL-8 activity have $\sim 84 \%$ recurrence-free survival at five-years (23). Serum IL- 8 levels are increased in $67 \%$ of patients with early and metastatic breast cancer (24). IL-8-overexpressing breast cancer cells are favored at bone metastasis sites (25). Consistent with these reports, we also found that high expression of IL-8 is directly associated with poor prognosis in luminal A type breast cancer patients, but not in luminal B type breast cancer patients. In addition, the levels of IL- 8 mRNA and protein expression are significantly increased in an in vitro model for tamoxifen resistance. Therefore, we demonstrated that IL-8 expression or the IL- 8 signaling pathway would be a cause of tamoxifen resistance. IL- 8 and its receptors may be therapeutic targets to overcome tamoxifen resistance.

Constitutive IL- 8 expression has been found in many human cancers, including breast and colon cancer, and it is also regulated by a variety of stimuli such as lipopolysaccharide (LPS), phorbol-12-myristate-13-acetate, IL-1, TNF, hypoxia and nitric oxide (26-28). The core IL-8 promoter region contains the binding sites for AP- $1, \mathrm{NF}-\kappa \mathrm{B}, \mathrm{CAAT} / \mathrm{enhancer}-$ binding protein (C/EBP) and NF-IL-6-like factors (29). Scherle et al (30) reported that LPS-induced IL-8 expression is blocked by UO126 treatment in monocytes. TNF- $\alpha$ and IL-1 upregulate IL- 8 expression through the activation of $\mathrm{NF}-\kappa \mathrm{B}$ 
in fibroblast-like synoviocytes (31). In this study, we observed that the activity of MEK and IL- 8 expression is significantly increased in TamR cells. On the contrary, increased IL- 8 levels are completely suppressed by the MEK $1 / 2$ inhibitor, UO126, in TamR cells. In contrast, CA-MEK overexpression triggers IL-8 mRNA expression in TamS cells. Therefore, we demonstrate that MEK activity plays an important role in regulating IL-8 expression in TamR cells.

Recently, CXC chemokine receptor 2(CXCR2), one of the IL- 8 receptors, was found to be associated with poor prognosis in intrahepatic cholangiocellular carcinoma (ICC) (32). Tumorigenesis and metastasis are significantly suppressed by both CXCR2 siRNA and the specific CXCR2 antagonist, SB225002 (32). Furthermore, CXCR1-specific blocking antibody or the CXCR1/2 inhibitor, repertaxin, are able to suppress the cancer stem cell population in human breast cancer xenografts, retarding tumor growth and reducing metastasis (33). In accordance with these reports, our results show that anchorage-independent growth of tamoxifen-resistant cells is completely suppressed by SB225002 treatment. The number of apoptotic cells is also increased in response to SB225002. Therefore, we suggest that CXCR1 and/or CXCR2 inhibitors such as repertaxin and SB225002 may be promising drugs for treating tamoxifen-resistant breast cancer patients.

In conclusion, we investigated the regulation of IL-8 expression and the effect inhibiting the IL- 8 receptor in TamR cells. Clinically, elevated IL- 8 expression is associated with poor prognosis in luminal A type breast cancer patients, but not in luminal B type breast cancer patients. In addition, the level of IL-8 expression and MEK activity is significantly increased in TamR cells. Elevated IL-8 expression is completely suppressed by the specific MEK inhibitor UO126, whereas, the basal level of IL-8 expression is increased by CA-MEK overexpression. Therefore, we demonstrate that a MEK-dependent pathway plays an important role in regulating IL- 8 expression in TamR cells. Finally, we found that the specific CXCR1/2 inhibitor SB225002 completely suppresses anchorage-independent growth and triggers apoptotic cell death in TamR cells. Finally, we suggest that a variety of specific CXCR1/2 inhibitors like SB225002 may be promising drug candidates for overcoming or bypassing tamoxifen resistance.

\section{Acknowledgements}

The present study was supported by a grant from the Korea Health Technology R\&D Project through the Korea Health Industry Development Institute (KHIDI), funded by the Ministry of Health \& Welfare, Republic of Korea (HI14C3418) and by the Basic Science Research Program through the National Research Foundation of Korea (NRF) funded by the Ministry of Education (2015R1D1A1A01057585).

\section{References}

1. Jemal A, Siegel R, Xu J and Ward E: Cancer statistics, 2010. CA Cancer J Clin 60: 277-300, 2010.

2. Jordan VC and O'Malley BW: Selective estrogen-receptor modulators and antihormonal resistance in breast cancer. J Clin Oncol 25: 5815-5824, 2007.
3. Jordan VC and Murphy CS: Endocrine pharmacology of antiestrogens as antitumor agents. Endocr Rev 11: 578-610, 1990.

4. Ring A and Dowsett M: Mechanisms of tamoxifen resistance. Endocr Relat Cancer 11: 643-658, 2004.

5. Davies C, Godwin J, Gray R, Clarke M, Cutter D, Darby S, McGale P, Pan HC, Taylor C, Wang YC, et al; Early Breast Cancer Trialists' Collaborative Group (EBCTCG): Relevance of breast cancer hormone receptors and other factors to the efficacy of adjuvant tamoxifen: Patient-level meta-analysis of randomised trials. Lancet 378: 771-784, 2011.

6. Kim S, Lee J, Oh SJ, Nam SJ and Lee JE: Differential effect of EGFR inhibitors on tamoxifen-resistant breast cancer cells. Oncol Rep 34: 1613-1619, 2015.

7. Maxwell PJ, Gallagher R, Seaton A, Wilson C, Scullin P, Pettigrew J, Stratford IJ, Williams KJ, Johnston PG and Waugh DJ: HIF-1 and NF-kappaB-mediated upregulation of CXCR1 and CXCR2 expression promotes cell survival in hypoxic prostate cancer cells. Oncogene 26: 7333-7345, 2007.

8. Collins TS, Lee LF and Ting JP: Paclitaxel up-regulates interleukin-8 synthesis in human lung carcinoma through an NF-kappaB- and AP-1-dependent mechanism. Cancer Immunol Immunother 49: 78-84, 2000.

9. Waugh DJ and Wilson C: The interleukin-8 pathway in cancer. Clin Cancer Res 14: 6735-6741, 2008.

10. Kassim SK, El-Salahy EM, Fayed ST, Helal SA, Helal T, Azzam ED and Khalifa A: Vascular endothelial growth factor and interleukin- 8 are associated with poor prognosis in epithelial ovarian cancer patients. Clin Biochem 37: 363-369, 2004.

11. Mayerhofer K, Bodner K, Bodner-Adler B, Schindl M, Kaider A, Hefler L, Zeillinger R, Leodolter S, Joura EA and Kainz C: Interleukin-8 serum level shift in patients with ovarian carcinoma undergoing paclitaxel-containing chemotherapy. Cancer 91: 388-393, 2001.

12. Miller LJ, Kurtzman SH, Wang Y, Anderson KH, Lindquist RR and Kreutzer DL: Expression of interleukin-8 receptors on tumor cells and vascular endothelial cells in human breast cancer tissue. Anticancer Res 18 (1A): 77-81, 1998.

13. Chavey C, Bibeau F, Gourgou-Bourgade S, Burlinchon S, Boissière F, Laune D, Roques S and Lazennec G: Oestrogen receptor negative breast cancers exhibit high cytokine content. Breast Cancer Res 9: R15, 2007.

14. Freund A, Chauveau C, Brouillet JP, Lucas A, Lacroix M, Licznar A, Vignon F and Lazennec G: IL-8 expression and its possible relationship with estrogen-receptor-negative status of breast cancer cells. Oncogene 22: 256-265, 2003.

15. Freund A, Jolivel V, Durand S, Kersual N, Chalbos D, Chavey C, Vignon F and Lazennec G: Mechanisms underlying differential expression of interleukin-8 in breast cancer cells. Oncogene 23: 6105-6114, 2004.

16. Martin D, Galisteo R and Gutkind JS: CXCL8/IL8 stimulates vascular endothelial growth factor (VEGF) expression and the autocrine activation of VEGFR 2 in endothelial cells by activating NFkappaB through the CBM (Carma3/Bcl10/Malt1) complex. J Biol Chem 284: 6038-6042, 2009.

17. Li A, Varney ML, Valasek J, Godfrey M, Dave BJ and Singh RK: Autocrine role of interleukin-8 in induction of endothelial cell proliferation, survival, migration and MMP-2 production and angiogenesis. Angiogenesis 8: 63-71, 2005.

18. Knowlden JM, Hutcheson IR, Jones HE, Madden T, Gee JM, Harper ME, Barrow D, Wakeling AE and Nicholson RI: Elevated levels of epidermal growth factor receptor/c-erbB2 heterodimers mediate an autocrine growth regulatory pathway in tamoxifenresistant MCF-7 cells. Endocrinology 144: 1032-1044, 2003.

19. Shi Z, Yang WM, Chen LP, Yang DH, Zhou Q, Zhu J, Chen JJ, Huang RC, Chen ZS and Huang RP: Enhanced chemosensitization in multidrug-resistant human breast cancer cells by inhibition of IL- 6 and IL-8 production. Breast Cancer Res Treat 135: 737-747, 2012.

20. Yang J, Wang Y, Gao Y, Shao J, Zhang XJ and Yao Z: Reciprocal regulation of 17beta-estradiol, interleukin-6 and interleukin-8 during growth and progression of epithelial ovarian cancer. Cytokine 46: 382-391, 2009.

21. Sansone P, Storci G, Giovannini C, Pandolfi S, Pianetti S, Taffurelli M, Santini D, Ceccarelli C, Chieco P and Bonafé M: p66Shc/Notch-3 interplay controls self-renewal and hypoxia survival in human stem/progenitor cells of the mammary gland expanded in vitro as mammospheres. Stem Cells 25: 807-815, 2007. 
22. Korkaya H, Paulson A, Charafe-Jauffret E, Ginestier C, Brown M, Dutcher J, Clouthier SG and Wicha MS: Regulation of mammary stem/progenitor cells by PTEN/Akt/beta-catenin signaling. PLoS Biol 7: e1000121, 2009.

23. Rody A, Karn T, Liedtke C, Pusztai L, Ruckhaeberle E, Hanker L, Gaetje R, Solbach C, Ahr A, Metzler D, et al: A clinically relevant gene signature in triple negative and basal-like breast cancer. Breast Cancer Res 13: R97, 2011.

24. Benoy IH, Salgado R, Van Dam P, Geboers K, Van Marck E, Scharpé S, Vermeulen PB and Dirix LY: Increased serum interleukin- 8 in patients with early and metastatic breast cancer correlates with early dissemination and survival. Clin Cancer Res 10: 7157-7162, 2004.

25. Singh B, Berry JA, Vincent LE and Lucci A: Involvement of IL-8 in COX-2-mediated bone metastases from breast cancer. J Surg Res 134: 44-51, 2006.

26. Singh JK, Simões BM, Howell SJ, Farnie G and Clarke RB: Recent advances reveal IL-8 signaling as a potential key to targeting breast cancer stem cells. Breast Cancer Res 15: 210, 2013.

27. Yuan A, Yang PC, Yu CJ, Chen WJ, Lin FY, Kuo SH and Luh KT: Interleukin-8 messenger ribonucleic acid expression correlates with tumor progression, tumor angiogenesis, patient survival, and timing of relapse in non-small-cell lung cancer. Am J Respir Crit Care Med 162: 1957-1963, 2000.
28. Xie K: Interleukin- 8 and human cancer biology. Cytokine Growth Factor Rev 12: 375-391, 2001.

29. Mukaida N, Okamoto S, Ishikawa Y and Matsushima K Molecular mechanism of interleukin-8 gene expression. J Leukoc Biol 56: 554-558, 1994.

30. Scherle PA, Jones EA, Favata MF, Daulerio AJ, Covington MB, Nurnberg SA, Magolda RL and Trzaskos JM: Inhibition of MAP kinase kinase prevents cytokine and prostaglandin E2 production in lipopolysaccharide-stimulated monocytes. J Immunol 161: 5681-5686, 1998.

31. Aupperle K, Bennett B, Han Z, Boyle D, Manning A and Firestein G: NF-kappa B regulation by I kappa B kinase-2 in rheumatoid arthritis synoviocytes. J Immunol 166: 2705-2711, 2001.

32. Sueoka H, Hirano T, Uda Y, Iimuro Y, Yamanaka J and Fujimoto J: Blockage of CXCR2 suppresses tumor growth of intrahepatic cholangiocellular carcinoma. Surgery 155: 640-649, 2014.

33. Ginestier C, Liu S, Diebel ME, Korkaya H, Luo M, Brown M, Wicinski J, Cabaud O, Charafe-Jauffret E, Birnbaum D, et al: CXCR1 blockade selectively targets human breast cancer stem cells in vitro and in xenografts. J Clin Invest 120: 485-497, 2010 . 